\title{
AS CONTRIBUIÇÕES DAS ATIVIDADES MUSICAIS PARA A FORMAÇÃO DO ALUNO NO 5 ANO DO ENSINO FUNDAMENTAL
}

\section{ARTIGO ORIGINAL}

OLIVEIRA, Marcus Mustafa de ${ }^{1}$

OLIVEIRA, Marcus Mustafa de. As contribuições das atividades musicais para a formação do aluno no $5^{\circ}$ ano do Ensino Fundamental. Revista Científica Multidisciplinar Núcleo do Conhecimento. Ano 04, Ed. 07, Vol. 07, pp. 130-141. Julho de 2019. ISSN: 2448-0959

\section{RESUMO}

Este trabalho de pesquisa tem como objetivo mostrar as contribuições das atividades musicais para a construção de conhecimentos significativos no $5^{\circ}$ ano do Ensino Fundamental na escola Municipal Solange Nascimento, Manaus - Amazonas. Para esta compreensão, objetivou-se, principalmente, investigar como as atividades musicais podem auxiliar na aplicabilidade da interdisciplinaridade e no processo de ensino e aprendizagem dos discentes. As metodologias utilizadas foram abordagem qualiquantitativa, pesquisa de campo e de levantamento surveys e as técnicas empregadas foram questionário semiestruturado. Foram pesquisados um grupo de 35 alunos sobre os benefícios que as atividades musicais proporcionam no processo de ensino-aprendizagem. $\mathrm{O}$ estudo constatou que, dos educandos envolvidos nas atividades musicais $68 \%$ melhoram suas notas em todas as disciplinas, bem como seus comportamentos em sala de aula. O estudo verificou também que $70 \%$ dos estudantes melhoraram suas capacidades cognitivas de percepção e psicomotoras,

${ }^{1}$ Mestrando em Ciências da Educação, Saint Alcuim (2016- ), Especialização em Administração Escolar, Ucam (2006) Complementação Pedagógica em História, Fest (2005), Bacharelado em Teologia, Fatebov (2003). 
por meio das atividades musicais. Atualmente, há na escola dois trabalhos envolvendo atividades musicais, oferecido aos alunos de forma interdisciplinar e facultativa.

Palavras-chave: Aprendizagem, interdisciplinaridade, atividades artísticas.

\section{INTRODUÇÃO}

As atividades artísticas no Ensino Fundamental, em especial a Educação Musical tem possibilitado, através da vivência das dimensões estéticas, sonoras, visuais, plásticas e gestuais, desenvolver a capacidade cognitiva, a consciência crítica dos valores humanos nos alunos e propiciar um conhecimento reflexivo como cidadãos. A Arte vem sendo tratada, na maioria das escolas brasileiras, como suporte para as demais disciplinas que compõe o quadro curricular, fato que mostra o seu caráter interdisciplinar enquanto área do conhecimento humano.

De acordo com Graciano (2009, p. 2), "As linguagens artísticas, em especial a música, é uma das mais acessíveis e presentes no cotidiano dos alunos". Deste modo, a escola tem um papel muito importante no contato do estudante com esse tipo de manifestação cultural, posto que a Arte, segundo Duarte (1991), apresenta três dimensões importantes para a formação educacional do discente: a sociocultural, que aponta o pensamento artístico como causa da preservação da cultura de um determinado grupo social num determinado tempo; a dimensão currículo-escolar, na qual a arte como área específica leva o aluno a estabelecer conexões com outras disciplinas do currículo; e a dimensão psicológica, que observa a educação em arte como promotora de um pensamento capaz de fazer com que o indivíduo possa relacionar-se com outros levando em conta uma maior afetividade, além do desenvolvimento da criatividade. Assim, há uma série de aspectos relevantes que se leva a identificar a Arte na educação, em especial as atividades musicais como uma questão a ser mais discutida na comunidade escolar.

Nessa perspectiva, busca-se analisar a problemática da pesquisa em questão: As práticas de atividades musicais no $5^{\circ}$ ano do Ensino Fundamental na escola Solange Nascimento promovem a melhoria na qualidade do ensino-aprendizagem dos alunos? 
A partir dessa análise, algumas questões norteadoras são enfrentadas no desenvolvimento do estudo: Em que consiste as práticas de atividades musicais no $5^{\circ}$ ano do Ensino Fundamental na escola Solange Nascimento? Como essas práticas de atividades musicais têm proporcionado benefícios no aprendizado dos alunos? Como se dá as práticas de atividades musicais na escola Solange Nascimento?

Nesse sentido, as hipóteses que nortearam a pesquisa foram formuladas nos seguintes termos: As práticas de atividades musicais como meio para a promoção na qualidade do ensino dos alunos do $5^{\circ}$ ano da escola Solange Nascimento;

As práticas de atividades musicais como suporte no processo de ensinoaprendizagem dos discentes da escola Solange Nascimento;

Acredita-se que o esforço teórico para tentar responder a estas questões se justifica na medida em que os resultados da pesquisa podem eventualmente contribuir para uma reflexão crítica sobre o modo como as atividades musicais oferecidas na escola Solange Nascimento, de fato tem ajudado na melhoria da qualidade do ensino dos alunos.

Nessa perspectiva, o objetivo principal da pesquisa constitui-se em: Analisar como se dá o processo das práticas de atividades musicais no $5^{\circ}$ ano do Ensino Fundamental na escola Solange Nascimento.

Os objetivos mais específicos são: Investigar as práticas das atividades musicais no $5^{\circ}$ ano do Ensino Fundamental na escola Solange Nascimento; identificar as atividades musicais oferecidas pela a escola aos alunos do $5^{\circ}$ ano; e descrever como se dá as práticas das atividades musicais no 5ํan ano do Ensino Fundamental na escola Solange Nascimento.

Entendemos que o estudo sobre as atividades musicais nos possibilita examinar todos os aspectos da contribuição da Arte no processo de ensino-aprendizagem do aluno. Portanto, esta pesquisa poderá ajudar a entender os benefícios que as atividades musicais proporcionam aos discentes, o que confirma sua relevância. Dessa forma, se pode elencar como principais contribuições deste estudo: 
a) Fornecer um diagnóstico das contribuições das atividades musicais no processo de ensino-aprendizagem dos alunos de $5^{\circ}$ ano da escola Municipal Solange Nascimento, no município de Manaus, AM, o qual abrirá caminhos para o desenvolvimento de futuras análises sobre os benefícios que as atividades musicais proporcionam a comunidade escolar, contribuindo ainda para o aprofundamento do conhecimento científico acerca, principalmente, das atividades artísticas oferecidas nas escolas públicas de Manaus;

b) E, finalmente, servir de fonte de referência e de conhecimento científico aos demais pesquisadores e instituições científicas sobre a importância das atividades musicais como ferramenta de ensino-aprendizagem à comunidade escolar.

\section{REFERENCIAL TEÓRICO}

No Brasil, a Lei de Diretrizes e Bases para a Educação Nacional - LDB no 9.394/96 no Artigo 26, inciso 2º , estabelece a obrigatoriedade do Ensino de Arte na Educação Básica, que compreende a Educação Infantil, o Ensino Fundamental e o Ensino Médio, legitimando a Arte enquanto Área Curricular. Os Parâmetros Curriculares Nacionais - PCN, para as séries iniciais do Ensino Fundamental, volume 06, relativo à área Curricular Arte, apontam a educação em Arte como forma de propiciar o desenvolvimento do pensamento artístico, além de proporcionar, a muitos indivíduos, uma relação afetiva com o meio em que vivem. Os (PCN, 1997) também apresentam a Arte como uma das possibilidades de valorização do ser humano através de suas diferentes formas de manifestação.

Corroborando com essa ideia, segundo Ferraz; Fusari (2001, p.19-22), a educação através da Arte é, na verdade um movimento educativo e cultural que busca a constituição de um ser completo, total, dentro dos moldes do pensamento idealista e democrático, valorizando no ser humano os aspectos intelectuais, morais e estéticos, procura despertar sua consciência individual e harmonizada ao grupo social ao qual pertence.

Ainda ressaltando o assunto, Martins; Picosque; Guerra (1998) afirmam que: 
A comunicação entre as pessoas e as leituras de mundo não se dão apenas por meio da palavra. Muito do que se sabemos sobre o pensamento e os sentimentos das mais diversas pessoas, povos, países, épocas são conhecimentos que obtivemos única $e$ exclusivamente por meio de suas músicas, teatro, pintura, dança, cinema, etc. (MARTINS; PICOSQUE; GUERRA,1998, P.14).

Para Visconti e Biagioni (2002, p. 8), "O ensino musical na escola promove o acesso dos alunos aos bens culturais [...]". Disso, decorre a importância das práticas das atividades musicais no meio escolar. Segundo essas autoras, "a música é, sem dúvida, uma das mais valiosas formas de expressão da humanidade" (2002, p. 9).

De acordo com Visconti e Biagioni (2002), o trabalho com a música no Ensino Fundamental possibilita uma variedade de modos de percepção e sensações do aluno na sua relação com o mundo, por meio dos recursos expressivos de que dispõe o seu organismo para a comunicação e o conhecimento de mundo em que ele vive.

A educação artística, de modo geral considera os sentimentos e os valores, como também as habilidades cognitivas: a criação, a reflexão como meio de proporcionar ao aluno uma interação lúdica por meio da música, a partir do nível sensorial, trabalhando-se assim, sua percepção, até atingir o nível da sensibilidade, responsável pelo aprimoramento mental do discente. Desta forma, se percebe que a atividade musical é de grande relevância, pois possibilita o desenvolvimento do córtex cerebral, melhorando as habilidades intelectuais vitais dos alunos.

Corroborando com essa afirmativa, (JAMES, 1997) ressalta que, pesquisa feita com mais de vinte e cinco mil (25.000) estudantes por um período de dez anos, [...] "mostrou que a música melhora os resultados dos testes". Independentemente do histórico socioeconômico; estudantes que participam de atividades musicais conseguem notas melhores nos testes padronizados, bem como, na leitura de exames de proficiência.

Também, nessa perspectiva, os (PCNS, 1997) citam que: 
O ser humano que não conhece a arte tem uma experiência de aprendizagem limitada, escapa-Ihe a dimensão do sonho, da força comunicativa dos objetos à sua volta, da sonoridade instigante da poesia, das criações musicais, das cores e formas, dos gestos e luzes que buscam o sentido da vida. (PCN,1997, p. 89).

Segundo Visconti e Biagioni (2002, p. 9), Estudos científicos comprovam que a participação em atividades musicais aumenta a habilidade do aluno em aprender matemática básica e leitura e, estudantes que participam de programas de música obtêm notas significativas mais altas nos testes, bem como, autodisciplina e sensibilidade. De acordo com os (PCNs, 1997), "É necessário procurar e repensar caminhos que nos ajudem a desenvolver uma educação musical que considere o mundo contemporâneo em suas características e possibilidades culturais, que contribuía para a humanização de nossos alunos".

Reforçando a citação dos (PCNs, 1997), a Associação Brasileira de Música, (2002, p. 78) assegura que, "A importância da música para os alunos aprender a tocar um instrumento musical é uma experiência compensadora para qualquer pessoa de qualquer idade, mas a música é especialmente útil ao desenvolvimento dos alunos na fase de ensino-aprendizagem".

Observa-se que atividades musicais são fatores preponderantes no estímulo a aprendizagem. Fonterrada apud Schafer, (1992) cita que:

Abre-te! Abre-te ouvido, para os sons do mundo, abre-te ouvido para os sons existentes, desaparecidos, imaginados, pensados, sonhados, fruídos! Abre-te para os sons originais, da criação do mundo, do início de todas as eras... Para os sons rituais, para os sons míticos, místicos, mágicos. Encantados... Para os sons de hoje e de amanhã. Para os sons da terra, do ar e da água... Para os sons cósmicos, microcósmicos, macrocósmicos... Mas abre-te também para os sons de aqui e de agora, para os sons do cotidiano, da cidade, dos campos, das máquinas, dos 
animais, do corpo, da voz... Abre-te, ouvido, para os sons da vida... (FONTERRADA apud SCHAFER, 1992, p. 10 -11).

A música é parte integrante da formação humana. Sempre interagindo com seu meio, o homem concebeu e confeccionou instrumentos variados, criou e exercitou diferentes cânticos, desenvolvendo com a linguagem musical uma relação cada vez mais rica e múltipla. Segundo Brito (1998, p. 134), "A música é uma forma de linguagem que faz parte da cultura humana desde tempos remotos. É uma forma de expressão e comunicação e se realiza por meio da apreciação e do fazer musical".

Observa-se que as atividades artísticas não são somente práticas de estímulos ao ensino-aprendizagem, mas também auxilia nas outras áreas de conhecimento como língua Portuguesa, Matemática, Geografia, Ciências, História, entre outras, por meio da interdisciplinaridade.

\section{MATERIAL E MÉTODOS}

As metodologias empregadas foram abordagem qualiquantitativa, pesquisa de campo e levantamento surveys. A opção por essa metodologia deu-se pelo fato de explicar um problema a partir de referências já publicadas sobre o assunto, de acordo com Gil (2006, p. 65). A partir do levantamento surveys proposto por Gil (2006, p. 70), obtevese o "conhecimento direto da realidade; quantificação dos dados, por meio de análise estatística e pesquisa de campo", Gil (2006, p. 128). Os dados foram coletados através de questionários, aplicados aos alunos da escola Municipal Solange Nascimento da Rede Municipal de Ensino de Manaus, no período de julho a dezembro de 2016, baseados nos benefícios que as atividades musicais propostas pelo professor proporcionaram aos alunos do $5^{\circ}$ ano do Ensino Fundamental. 


\subsection{UNIVERSO E AMOSTRA}

Tabela 1. População investigada e índice de amostragem

\begin{tabular}{|l|l|l|}
\hline & \multicolumn{2}{|l|}{ Alunos } \\
& Fn & F\% \\
\hline População & 112 & $100 \%$ \\
\hline Amostragem & 35 & $31,25 \%$ \\
\hline
\end{tabular}

Fonte: Escola Municipal Solange Nascimento (2016).

Conforme se demonstra na tabela 1, o número de alunos investigados representa $31,25 \%$ de um universo de 112 alunos do $5^{\circ}$ ano do Ensino Fundamental da escola Municipal Solange Nascimento.

\section{RESULTADOS E DISCUSSÃO}

Neste capítulo apresentam-se os dados quantitativos referentes ao corpus constituído e as interpretações qualitativas. Iniciamos com as análises de dados do perfil dos alunos e em seguida, tratamos dos dados coletados com base nos objetivos propostos. 


\subsection{DADOS DOS ALUNOS INVESTIGADOS}

Quadro 1. Perfil dos alunos investigados do $5^{\circ}$ ano do Ensino Fundamental

\begin{tabular}{|l|l|}
\hline Total de alunos & 35 \\
\hline Turno de estudo & Matutino \\
\hline Sexo masculino & 19 \\
\hline Sexo feminino & 16 \\
\hline Frequentando regularmente às aulas & $98 \%$ \\
\hline Índice de evasão & $2 \%$ \\
\hline Média de tempo de estudo & 7 anos \\
\hline Nível de ensino & $5^{\circ}$ ano do Ensino Fundamental \\
\hline Idade & Entre 10 a 12 anos \\
\hline
\end{tabular}

Fonte: Escola Municipal Solange Nascimento (2016).

Conforme se observa no quadro 1, em relação ao gênero do grupo pesquisado, há predomínio do sexo masculino com $54,28 \%$, enquanto os alunos do sexo feminino representam $45,72 \%$. No quesito frequência, dos 35 alunos, $98 \%$ estão frequentados regularmente às aulas e o índice de evasão é apenas de $2 \%$. A média de tempo de estudo dos alunos é de 7 anos, contados a partir do ingresso na Educação Infantil e, a faixa-etária é de 10 a 12 anos.

\subsection{ANÁLISES DOS DADOS COLETADOS COM BASE NOS OBJETIVOS}

\subsubsection{O PROCESSO DAS PRÁTICAS DE ATIVIDADES MUSICAIS NO 5 ANO DO ENSINO FUNDAMENTAL}

No processo de construção das práticas de atividades musicais, três aspectos foram trabalhados pelo professor: 
a) Apreciação musical - O sentir e o perceber, os quais são formas de apreciação e apropriação das criações artísticas. Foi desenvolvido através da visualização e da audição de experiências já feitas e composições criadas por diversos artistas com a utilização de materiais alternativos, a fim de despertar a sensibilidade estética e artística. O uso criativo de materiais alternativos para a realização musical, análises em vídeos e escutas de CDs, foram colocados em discussão e estudo durante as aulas.

b) Execução musical - Foram realizadas práticas musicais individuais e em grupo, com o objetivo de desenvolver a musicalidade com os instrumentos escolhidos (flautas), formando conceitos musicais através da aquisição de habilidades com o manuseio do som criado com o instrumento de sopro. Foram trabalhadas as qualidades do som: altura, duração intensidade e timbre, mencionadas conforme os questionamentos durante as experimentações com os instrumentos.

c) Composição musical - Processo que possibilitou com que os alunos produzissem um trabalho artístico com os instrumentos, desenvolvendo suas capacidades cognitivas, afetivas e psicomotoras através de combinações de sons, movimentos corporais e canto. Os alunos experimentaram esse processo de maneira individual e em grupo, de modo a se expressar pela música, com os instrumentos musicais e canto. 


\subsubsection{IDENTIFICAÇÃO DAS ATIVIDADES MUSICAIS OFERECIDAS PELA ESCOLA AOS ALUNOS DO 5 ANO}

Gráfico 1. Atividades musicais

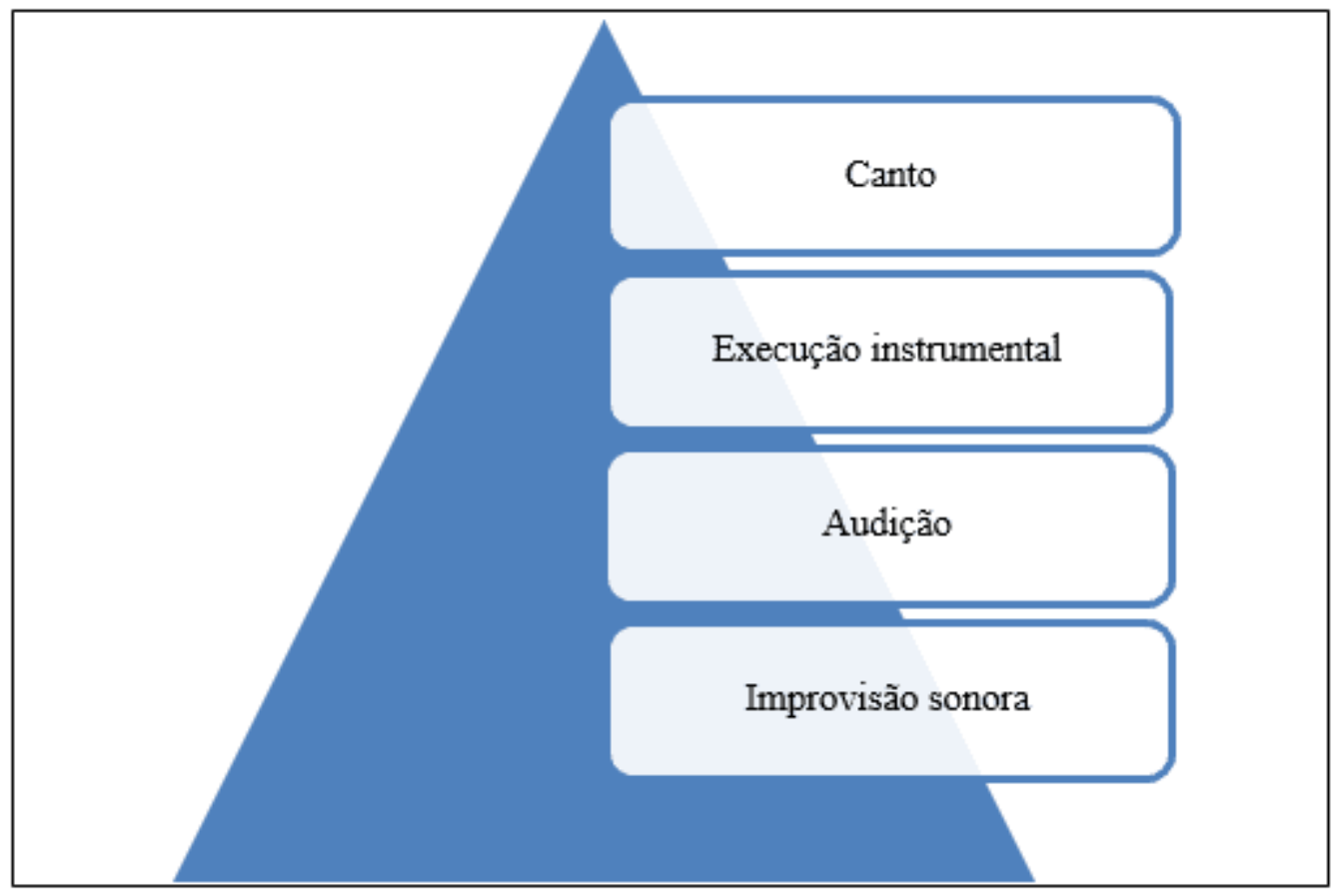

Fonte: Escola Solange Nascimento, 2016

As atividades musicais identificadas no gráfico 1, são habilidades que têm como propósito, além de contribuir para a socialização dos alunos e aproximá-los de manifestações da cultura, aprender música e conhecer mais sobre a expressão por meio dos sons e desenvolver tais habilidades nos discentes. Essas modalidades de atividades musicais são previstas na Lei ํㅜ 11.769, de 18 de agosto de 2008, que obriga o ensino desse conteúdo nas aulas de Arte.

As atividades propostas desenvolvem as habilidades de audição (familiarização com diferentes ritmos e estilos), percepção (de variações de sons e de timbres dos instrumentos), movimento corporal (dança e gestual) e experimentação (de instrumentos, de canto etc.). Propicia diferentes vivências para os alunos e é muito importante para que eles compreendam a música como uma linguagem dotada de 
sentido e associada à cultura de cada época. Até o fim do $5^{\circ}$ ano, é importante que todos aprendam as diferenças entre grave-agudo, forte-fraco e lento-rápido, conheçam alguns instrumentos, consigam marcar o pulso (a unidade de tempo que compõe o compasso, a "batida" da música), saibam cantar melodias, serem capazes de ler com fluência e trabalhar melodias um pouco mais complexas no canto.

\subsubsection{DESCRIÇÃO DAS PRÁTICAS DE ATIVIDADES MUSICAIS NO 5 ANO DO ENSINO FUNDAMENTAL}

As atividades musicais são desenvolvidas semanalmente, em duas aulas de, no mínimo, meia hora e a aula começa com exercício de audição de uma música tranquila, seguida das atividades de percepção e das vivências de canto e percussão. Segue uma sequência musical de variação de altura e intensidade sonora nas melodias. Essas atividades musicais seguem uma rotina pré-estabelecida construída de forma conjunta e avaliada semanalmente pelo professor.

As contribuições das atividades musicais no processo de ensino-aprendizagem, conforme citados pelos alunos foram descritas, conforme se observa no quadro 2 : 
Quadro 2. As contribuições das atividades musicais no processo de ensinoaprendizagem do aluno

\begin{tabular}{|l|l|}
\hline $\begin{array}{l}\text { Atividade } \\
\text { musical }\end{array}$ & $\begin{array}{l}\text { Contribuições para o ensino-aprendizagem do aluno } \\
\text { Canto }\end{array}$ \\
& $\begin{array}{l}\text { Os alunos desenvolveram impostação da voz, auto expressão, } \\
\text { autoestima, experiência em conjunto, autodisciplina, } \\
\text { desenvolvimento das relações sociais, entretenimento, a } \\
\text { concentração e o desenvolvimento do raciocínio. }\end{array}$ \\
\hline $\begin{array}{l}\text { Execução } \\
\text { instrumental }\end{array}$ & $\begin{array}{l}\text { Os alunos desenvolveram a criatividade, a imaginação, o } \\
\text { pensamento e a coordenação motora }\end{array}$ \\
\hline Audição & $\begin{array}{l}\text { Os alunos desenvolveram a sensibilidade, a percepção e os } \\
\text { sentimentos }\end{array}$ \\
\hline $\begin{array}{l}\text { Improvisação } \\
\text { sonora }\end{array}$ & $\begin{array}{l}\text { Os alunos desenvolveram a imaginação, a intuição, a sensação e } \\
\text { o processo criador }\end{array}$ \\
\hline
\end{tabular}

Fonte: Fonte: Alunos do $5^{\circ}$ ano da escola Solange Nascimento, 2016

Conforme se observa no quadro 2, foram inúmeras as contribuições proporcionadas pelas atividades musicais aos alunos. Graciano $(2009$, p. 2) afirma que, "Entre as linguagens artísticas, a música é uma das mais acessíveis e presentes no cotidiano dos alunos". Desta forma, se percebe que as atividades musicais são essenciais no processo de ensino-aprendizagem dos alunos, haja vista que ajuda no desenvolvimento de várias habilidades necessárias a vida educacional. Somam-se a isso também, os benefícios adquiridos por meio das atividades musicais, conforme informaram os alunos no gráfico 2: 
Gráfico 2. Benefícios adquiridos pelos alunos

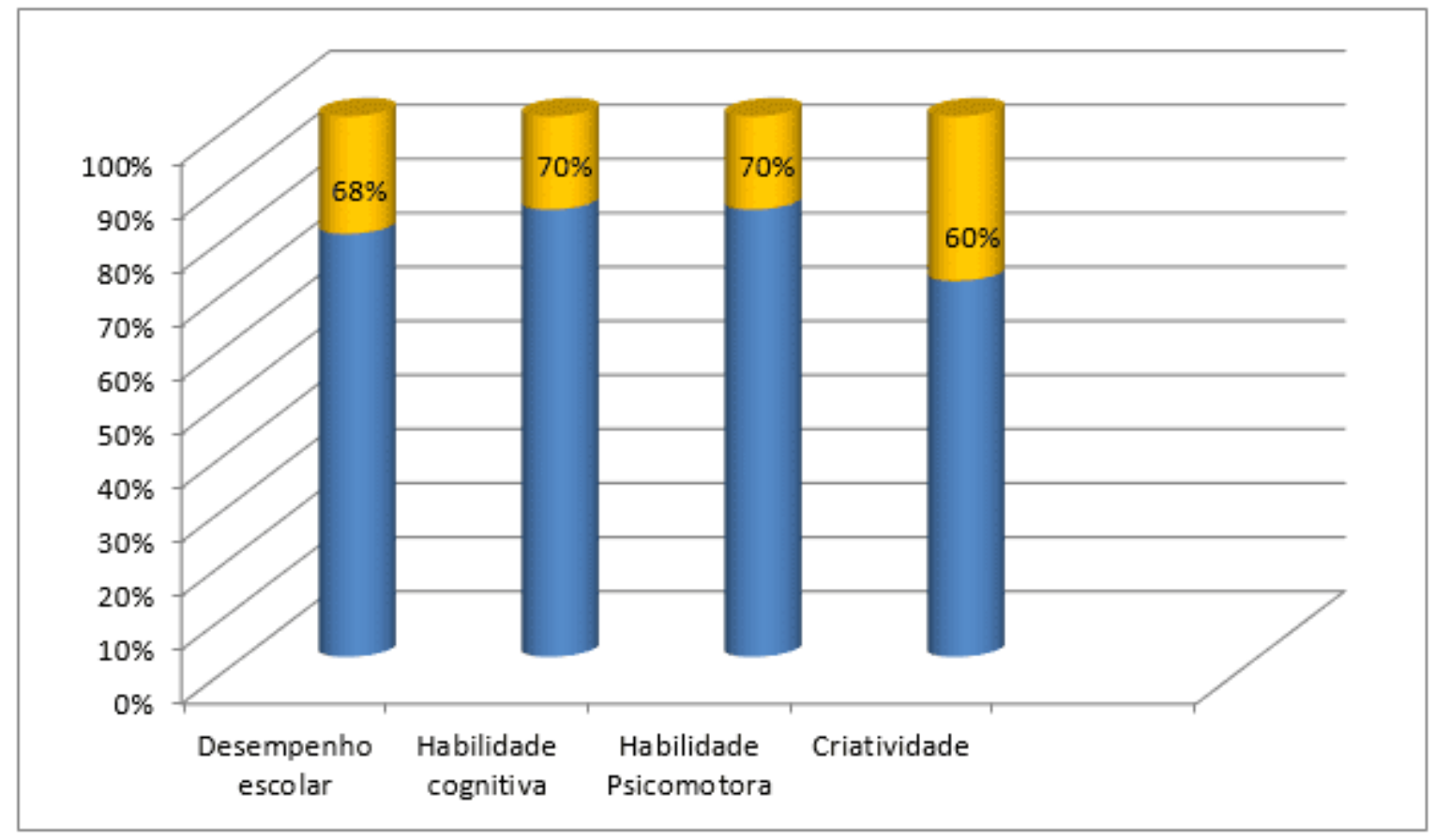

Fonte: Alunos do 5ำ ano da escola Solange Nascimento, 2016

O estudo constatou que, dos educandos envolvidos nas atividades musicais $68 \%$ melhoram seus desempenhos escolares, bem como seus comportamentos em sala de aula. O estudo verificou também que $70 \%$ dos estudantes melhoraram suas capacidades cognitivas e psicomotoras e, ainda $60 \%$ dos discentes disseram ter melhorado na criatividade, por meio das atividades musicais. Percebe-se assim que, a educação pela atividade musical é o meio adequado para aprimorar eficazmente a socialização individual dos alunos, o clima social na escola e a chamada capacidade de empatia, porque a música estimula emocionalmente, equilibra as tensões, favorece os contatos e a capacidade de experiência. Como espaço livre e um campo experimental para a fantasia estético musical e sociomusical, a atividade musical demonstrou-se ser indispensável no processo de ensino-aprendizagem dos alunos. Visto que, além de favorecer o processo de ensino interdisciplinar entre as disciplinas do currículo, também auxilia no processo de construção do conhecimento, favorecendo o desenvolvimento da sensibilidade, da criatividade, do senso rítmico, da imaginação, da memória, da concentração e da atenção dos discentes. 


\section{CONCLUSÃO}

Procurou-se enfocar nesse estudo a contribuição da atividade musical para o ensinoaprendizagem no Ensino Fundamental, a qual tem trazido benefícios a comunidade de estudantes do $5^{\circ}$ da escola Municipal Solange Nascimento, na complementação da formação artística e nos seus desenvolvimentos educacionais, sob os quais as possibilidades de aprendizado têm ampliado seus conhecimentos de forma plena. Fato este que se percebeu no decorrer desta pesquisa, de como as linguagens musicais foram percebidas sensorialmente e objetivadas em diferentes organizações simbólicas dos alunos. O contato com as linguagens musicais envolveu recepção e produção de representações no exercício da expressividade movida pela imaginação dos alunos. Nesse sentido, as linguagens musicais apareceram como formas de apropriação do mundo, próximas dos discentes por serem inicialmente corporais, sonoras e atrativas, as quais são meios privilegiados de apropriação de relações e construção de conceitos pelos alunos. Desta forma, para responder aos objetivos e as hipóteses suscitadas sobre as práticas de atividades musicais como meio para a promoção na qualidade do ensino dos alunos do $5^{\circ}$ ano e de atividades de suporte no processo de ensino-aprendizagem dos discentes da escola Municipal Solange Nascimento, verificou-se que os benefícios das atividades musicais sugeridas pela escola sustentam a ação docente no processo de ensino, de forma flexível e prazerosa na promoção de experiências sonoro-musicais inovadoras. Entre elas, atividades de sensibilização sonora e desenvolvimento de habilidades com instrumentos de sopro de percussão; relaxamento, respiração e aquecimento vocal; dicas para o cuidado com a impostação da voz; atividades com os sons da flauta doce; manuseio de instrumentos de sopro; registro e notação, entre outros.

Assim, as ações expressas por meio das atividades musicais contribuem com o repertório cultural partilhado na produção e recepção de representações com as linguagens artísticas dos alunos. $\mathrm{O}$ contato com as atividades musicais no Ensino Fundamental fornece amplo conhecimento cultural necessário para a compreensão e representação de mundo pelos alunos. 


\section{REFERÊNCIAS}

ASSOCIAÇÃO BRASILEIRA DE MÚSICA. A importância da música para as crianças. $1^{a}$ ed. STA Comunicação, 2002.

BRASIL. Ministério da Educação e do Desporto. Secretaria de Educação Fundamental. Lei de Diretrizes e Bases da Educação Nacional, LDB. Lei no 9.394, de 20 de dezembro de 1996. Brasília: MEC/SEF, 1996.

BRASIL. Secretaria de Educação Fundamental. Parâmetros Curriculares Nacionais: Arte. Volume 6 - Brasília: MEC/SEF, 1997.

BRASIL. Presidência da República. Lei no 11.769 de agosto de 2008. Altera a Lei no 9.394 de 20 de dezembro de 1996, Lei de diretrizes e bases da educação, para dispor sobre a obrigatoriedade do da música na educação básica. Brasília, 2008.

BRITO, Teca de Alencar, Música na Educação Infantil. São Paulo: Papirus, 1998.

CATTERALL, James. How Music Can Dramatically Affect Your Child's Development and Life-Time Success. US, UCLA, 1997.

DUARTE JÚNIOR, João Francisco. Porque Arte-Educação? 6. ed. Campinas, SP: Papirus, 1991.

FERRAZ, M H C. de T.; FUSARI, M.F de R. Arte na Educação Escolar. 4. Reimpressão. Coleção Magistério. São Paulo: Cortez, 2001.

GIL, Antônio Carlos. Métodos e técnicas de pesquisa social. 5 ed. São Paulo: Atlas, 2006.

MARTINS, M.C.; PICOSQUE, G.; GUERRA, M. T.T. Didática do Ensino de Arte: A Língua do Mundo: Poetizar, fruir e conhecer arte. São Paulo: FTD, 1998.

NADAL, Paula. O ensino da música em sete notas. NOVA ESCOLA Edição 245, 01 de Setembro de 2011. 
SCHAFER, R. Murray; FONTERRADA, Marisa. O ouvido Pensante. São Paulo. Editora da UNESP, 1992.

VISCONTI, Márcia; BIOGIONI, Maria Zei. Educação Musical e Prática Musical em Escolas. São Paulo: ABEMUSICA, 2002.

Enviado: Abril, 2019.

Aprovado: Julho, 2019. 